\title{
High mortality by natural and unnatural causes: a 10 year follow up study of patients admitted to a poisoning treatment centre after suicide attempts
}

\author{
Merete Nordentoft, Leif Breum, Lars K Munck, Aksel G Nordestgaard, Alex Hunding, \\ Peder A Laursen Bjældager
}

\begin{abstract}
Objective-To describe mortality by suicide and other causes of death in a group of patients who attempted suicide, and to identify predictive factors.

Design-10 year follow up study based on records of suicide attempters in 1980.

Setting-Poisoning treatment centre at a general hospital.

Subjects-974 patients aged 15 and over referred to the poisoning treatment centre after deliberate self poisoning.

Main outcome measures-Death by different causes registered in the Danish death cause register.

Results-In 10 years of follow up 306 patients died: 103 by suicide, 131 from natural causes, and 31 by accidents; five were murdered, and in 36 cases the cause of death was uncertain. The standard mortality ratio was $\mathbf{5 5 0}$. Cause specific standardised mortality rates were 2960 for suicide, 236 for natural causes, 1256 for accidents, and 5459 for uncertain causes. In a Cox regression analysis, high risk factors for subsequent suicide were: more than one previous suicide attempt (relative risk $2 \cdot 25$ ), living alone $(2 \cdot 28)$, and age $(1.03$ per year). Predictors of death by natural causes were receiving a pension (1.69), drug misuse $(2 \cdot 72)$, more than one previous suicide attempt $(2.25)$, age ( 1.06 per year), and male sex (2.49). The group of patients fulfilling at least one high risk criterion for later suicide differed significantly from the rest of the patient group in incidence of suicide, but both sensitivity and specificity were low.
\end{abstract}

Conclusions-Most patients who attempted suicide were at high risk of succeeding because the risk factors, though significant, are not very specific. A strategy to prevent suicide must be directed toward the majority of those who attempt suicide.

\section{Introduction}

Each year between 1300 and 1400 people commit suicide in Denmark, a male:female ratio of about $1 \cdot 7: 1$. Next to Hungary, Denmark has the highest suicide rate in the world. ${ }^{1}$ In 1980 the suicide rate per 100000 inhabitants in Copenhagen was 41.4 for men and 27.9 for women. ${ }^{2}$ These high rates emphasise the importance of this problem. Suicide and suicide attempts are serious problems-attempted suicide is the most common cause of hospital admission in the young age group ( 15 to 34 years), and suicide, next to accidents, is the most common cause of death in this age group. ${ }^{3}$

Several follow up studies previously carried out in the Scandinavian countries ${ }^{4-13}$ show a drastically increased suicide rate among people who have attempted suicide compared with the general popula- tion. ${ }^{4-13}$ Severe mental illness, social isolation, male sex, alcohol abuse, several previous suicide attempts, and physical illness have been shown to be risk factors. Several studies have concluded that, especially during the first year after a suicide attempt, there is a risk of a repeated suicide attempt and of succeeding.

The purpose of the study was to extract social and diagnostic predictors for suicide and other causes of death in a group of people who attempted suicide. Another purpose was to create an empirical basis for establishing an intervention programme for people who have attempted suicide or have suicidal intentions.

\section{Methods}

This follow up study was based on evaluation of records of all patients who in 1980 were admitted to the Poisoning Treatment Centre at Bispebjerg Hospital after deliberate self poisoning. ${ }^{14}$ The centre received all cases of self poisoning in the catchment area of the hospital (a population of about 200000 ). Patients from the rest of the municipality of Copenhagen (about 300000 inhabitants) and the county of Copenhagen could be admitted under certain circumstances: if they were unconscious after intoxication with morphinomimetics or anxiolytics; if their medical history or clinical condition suggested severe intoxication with neuroleptics or antidepressants; and if there was evidence of intoxication with salicylate or paracetamol. Thus, the sample was not representative of all who attempted suicide in the catchment areas, but biased toward the most seriously affected cases. The total number of suicide attempts in Copenhagen in 1980 was not registered, but on the basis of a comparison of the admission rates at the Poisoning Treatment Centre form the catchment area of Bispebjerg Hospital with the rest of Copenhagen it can be estimated that half of the patients from the rest of Copenhagen were treated at other hospitals. This comparison assumes an equal rate of suicide attempts in all areas of Copenhagen.

In 1980 there were 1249 admissions of 1105 patients at the Poisoning Treatment Centre. Among them, 14 died during the admission, 96 were admitted because of accidental poisoning, and 25 could not be followed up because they moved abroad. The remaining 974 , who were admitted after deliberate self poisoning and survived the index attempt, were included in the investigation. Information about sex, age, civil status, occupation, psychiatric diagnosis, previous suicide attempts, admission to psychiatric departments, and injury due to the self poisoning was extracted from the database of the original records.

This cohort of patients was investigated in the Danish population register, where it is possible to locate and trace individuals over time. Then all deaths were investigated in the death cause register at the 
Danish Institute of Clinical Epidemiology with regard to the International Classification of Diseases (ICD) codes for cause of death. Under Danish legislation, the cause of death must in all cases be certified by a doctor, and in cases where natural death is not certain a coroner's inquest is held. The term "uncertain cause" is used when the cause of death cannot be determined as either natural cause, accident, suicide, or homicide. No changes in legislation or administrative practice occurred during the follow up period.

The cause of death was thus divided into five groups: natural death, ICD codes 000-780; accidents, 800-949; suicide, 950-959; homicide, 960-969; and uncertain cause of death, 980-989. The natural causes of death were divided into subgroups. ${ }^{15}$ The subgroup "ill defined conditions" covers sudden non-violent deaths and deaths on admission (mortuus admissus).

Data were analysed by using the $\chi^{2}$ test, log rank test, ${ }^{16}$ Cox proportional hazards model, ${ }^{17}$ age specific mortality rates, and standard mortality rates. Mortality rates were compared to those in the general population with $\chi^{2}$ statistics based on mortality rates. ${ }^{18}$ Standard mortality rates are actual number of deaths of the cause under study among patients expressed as percentage of the expected number, which has been calculated as the follow up time of all patients in each sex and age specific group multiplied by the cause specific mortality in the corresponding group in the total Danish population. Mortality in the general population was calculated on basis of official statistics with information about causes of death in different sex and age groups in the total Danish population.

The patients were included in the study from the index admission in 1980 to the end of 1990, using time since admission as time variable. Patients who died

TABLE I-Characteristics of 974 people attempting suicide in Copenhagen in 1980

\begin{tabular}{|c|c|c|c|c|}
\hline & \multicolumn{2}{|c|}{$\begin{array}{c}\text { No }(\%) \\
\text { attempting suicide }\end{array}$} & \multicolumn{2}{|c|}{$\begin{array}{c}\text { No (\%) } \\
\text { later successful }\end{array}$} \\
\hline & $\underset{(n=412)}{\text { Men }}$ & $\begin{array}{l}\text { Women } \\
(n=562)\end{array}$ & $\begin{array}{c}\text { Men } \\
(n=48)\end{array}$ & $\begin{array}{l}\text { Women } \\
(n=55)\end{array}$ \\
\hline \multicolumn{5}{|l|}{ Age (years) } \\
\hline $15-24$ & $57(13 \cdot 8)$ & $80(14 \cdot 2)$ & $3(6 \cdot 3)$ & $3(5 \cdot 5)$ \\
\hline $25-34$ & $131(31 \cdot 8)$ & $132(23 \cdot 5)$ & $10(20 \cdot 8)$ & $12(21 \cdot 8)$ \\
\hline $35-44$ & $103(25 \cdot 0)$ & $146(26 \cdot 0)$ & $16(33.3)$ & $16(29 \cdot 1)$ \\
\hline $45-54$ & $62(15 \cdot 0)$ & $90(16 \cdot 0)$ & $11(22.9)$ & $9(16 \cdot 4)$ \\
\hline $55-64$ & $38(9 \cdot 2)$ & $58(10 \cdot 3)$ & $4(8 \cdot 3)$ & $4(7 \cdot 3)$ \\
\hline $65-74$ & $18(4 \cdot 4)$ & $43(7 \cdot 7)$ & $3(6 \cdot 3)$ & $8(14 \cdot 5)$ \\
\hline $75-84$ & $1(0 \cdot 2)$ & $11(2 \cdot 0)$ & 0 & $2(3 \cdot 6)$ \\
\hline$>85$ & $2(0 \cdot 5)$ & $2(0 \cdot 4)$ & $1(2 \cdot 1)$ & $1(1 \cdot 8)$ \\
\hline Living alonef & $96(23 \cdot 3)$ & $85(15 \cdot 1)$ & $17(35 \cdot 4)$ & $14(25 \cdot 5)$ \\
\hline Employed & $139(33 \cdot 7)$ & $185(32 \cdot 9)$ & $14(29 \cdot 2)$ & $13(23.6)$ \\
\hline \multicolumn{5}{|l|}{ Diagnosis ${ }^{\star}$} \\
\hline Schizophrenia & $16(3 \cdot 9)$ & $18(3 \cdot 2)$ & $2(4 \cdot 2)$ & $4(7 \cdot 3)$ \\
\hline Affective psychosis & $9(2 \cdot 2)$ & $29(5 \cdot 2)$ & $1(2 \cdot 1)$ & $7(12 \cdot 7)$ \\
\hline Psychogenic psychosis & $9(2 \cdot 2)$ & $15(2 \cdot 7)$ & $0(0 \cdot 0)$ & $2(3 \cdot 6)$ \\
\hline Neurosis & $24(5 \cdot 8)$ & $67(11.9)$ & $2(4 \cdot 2)$ & $7(12 \cdot 7)$ \\
\hline Personality disorder & $66(16 \cdot 0)$ & $64(11 \cdot 4)$ & $12(25 \cdot 0)$ & $8(14 \cdot 5)$ \\
\hline Alcoholism $\dagger$ & $156(37.9)$ & $86(15 \cdot 3)$ & $16(33 \cdot 3)$ & $12(21 \cdot 8)$ \\
\hline Drug addiction & $30(7 \cdot 3)$ & $15(2 \cdot 7)$ & $2(4 \cdot 2)$ & $1(1 \cdot 8)$ \\
\hline Other & $23(5 \cdot 6)$ & $48(8 \cdot 5)$ & $2(6 \cdot 3)$ & $7(16 \cdot 3)$ \\
\hline No mental illness & $117(28 \cdot 4)$ & $244(43 \cdot 4)$ & $13(40 \cdot 6)$ & $14(32 \cdot 6)$ \\
\hline No information & $15(3 \cdot 6)$ & $19(3 \cdot 4)$ & $3(9 \cdot 4)$ & 0 \\
\hline
\end{tabular}

${ }^{\star} \mathrm{p}<0.01$ for differences between men and woman at index attempt. tAlcoholism as first or second diagnosis. Total number of diagnoses exceed number of patients. during the follow up were followed to the registered date of death. The mean follow up time was 8.48 years.

The following variables were included in the proportional hazard model: age as a continuous variable; sex; cohabitation, categorised as living with others $=0$, living alone $=1$; employment, categorised as unemployed, student, disablement pensioner, or old age pensioner $=0$, employed $=1$; alcoholism, categorised as no daily consumption of alcohol $=0$, daily consumption of alcohol=1; pensioner, categorised as employed, student, or unemployed $=0$, old age pensioner or disablement pensioner $=1$; respirator treatment, categorised as no respirator treament $=0$ and respirator treatment $=1$; number of previous suicide attempts, categorised as no information about previous attempts, no previous attempts, one, two, three, or more previous attempts; psychiatric diagnosis, categorised as schizophrenia, affective psychosis, psychogenic psychosis, neurosis, personality disorder, alcoholism, drug addiction, other, and no mental illness. Each psychiatric diagnosis was tested against all other diagnoses, so new variables were created in which, for example, schizophrenia was categorised as all other diagnoses $=0$ and schizophrenia $=1$.

In the analysis of each cause of death, deaths from other causes than the specific one of interest were treated as censored values. In the proportional hazard test all variables were included and then excluded stepwise by the Wald test.

The probability of death from specific causes as function of follow up time was computed by Andersen's method. ${ }^{19} \mathrm{~A}$ p value $<0.05$ indicated significance. The software package BMDP was used in the Cox regression analysis.

The study was approved by the ethical committee of Copenhagen in accordance with the Helsinki declaration. Data from the cause of death register at the Danish Institute of Clinical Epidemiology were extracted with permission of Registertilsynet, the data surveillance authority.

\section{Results}

Table I shows characteristics of the patients surviving the suicide attempt in 1980 and the patients from the 1980 cohort who committed suicide during follow up. The records of these 974 people, investigated at the death cause register, showed that by the end of 1990, 306 had died (153 men, 153 women): 103 had committed suicide ( 48 men, 55 women), 131 died from natural causes ( 71 men, 60 women), 31 died by accidents (14 men, 17 women), five were murdered (2 men, 3 women), and in 36 cases the cause of death was uncertain ( $18 \mathrm{men}, 18$ women). In the group who died of uncertain causes, 34 of 36 died from acute alcohol intoxication

The standard mortality rate for all causes of death was high (both sexes: $550 ; \chi^{2}=1129 \cdot 1, \mathrm{df}=1$, $\mathrm{p}<0.0001$; men: $669 ; \chi^{2}=1129 \cdot 1, \mathrm{df}=1, \mathrm{p}<0.0001$; women: $\left.465 ; x^{2}=439 \cdot 2, \quad d f=1, \quad p<0 \cdot 0001\right)$. The observed to expected ratios (table II) were highest in

TABLE II-Age-specific mortality rates (deaths per 1000 per year) and cause specific rates for death from suicide and natural causes

\begin{tabular}{|c|c|c|c|c|c|c|c|c|c|}
\hline \multirow[b]{2}{*}{$\begin{array}{l}\text { Age } \\
\text { (years) }\end{array}$} & \multicolumn{3}{|c|}{ Age specific mortality rates } & \multicolumn{3}{|c|}{ Age specific suicide rates } & \multicolumn{3}{|c|}{ Age specific rates for natural cause of death } \\
\hline & $\begin{array}{c}\text { Suicide } \\
\text { attempters }\end{array}$ & $\begin{array}{c}\text { General } \\
\text { population }\end{array}$ & Rate ratio & $\begin{array}{l}\text { Suicide } \\
\text { attempters }\end{array}$ & $\begin{array}{c}\text { General } \\
\text { population }\end{array}$ & Rate ratio & $\begin{array}{c}\text { Suicide } \\
\text { attempters }\end{array}$ & $\begin{array}{c}\text { General } \\
\text { population }\end{array}$ & Rate ratio \\
\hline $15-24$ & 13.35 & 0.73 & $18 \cdot 29$ & $3 \cdot 34$ & $0 \cdot 12$ & $27 \cdot 83$ & 0 & $0 \cdot 19$ & 0 \\
\hline $25-34$ & 25.47 & 1.01 & $25 \cdot 22$ & $9 \cdot 36$ & $0 \cdot 32$ & $29 \cdot 25$ & $4 \cdot 68$ & 0.38 & $12 \cdot 32$ \\
\hline $35-44$ & 31.94 & $2 \cdot 02$ & $15 \cdot 81$ & 13.56 & 0.49 & $27 \cdot 67$ & $8 \cdot 31$ & 1.34 & $6 \cdot 20$ \\
\hline $45-54$ & $50 \cdot 68$ & $5 \cdot 40$ & $9 \cdot 38$ & $19 \cdot 27$ & 0.57 & $33 \cdot 81$ & $21 \cdot 41$ & 4.53 & $4 \cdot 73$ \\
\hline $55-64$ & 42.85 & $13 \cdot 27$ & 3.49 & $8 \cdot 79$ & 0.56 & $15 \cdot 70$ & $29 \cdot 66$ & $12 \cdot 36$ & $2 \cdot 40$ \\
\hline $65-74$ & $70 \cdot 25$ & $31 \cdot 23$ & $2 \cdot 25$ & $21 \cdot 62$ & 0.45 & $48 \cdot 04$ & 45.03 & $30 \cdot 27$ & 1.49 \\
\hline $75-84$ & $114 \cdot 68$ & $74 \cdot 47$ & 1.54 & $15 \cdot 54$ & 0.51 & $30 \cdot 47$ & 99.04 & $70 \cdot 67$ & $1 \cdot 40$ \\
\hline$\geqslant 85$ & $229 \cdot 67$ & $183 \cdot 38$ & $1 \cdot 25$ & $114 \cdot 84$ & 0.39 & $294 \cdot 46$ & $114 \cdot 84$ & $176 \cdot 17$ & 0.65 \\
\hline Standar & ortality ratio & & 550 & & & 2960 & & & 236 \\
\hline
\end{tabular}




\begin{tabular}{|c|c|c|c|c|c|}
\hline \multirow[b]{2}{*}{ Risk factor } & \multicolumn{5}{|c|}{ Relative risk for death $(95 \%$ confidence interval) } \\
\hline & $\begin{array}{l}\text { All causes of death } \\
(n=306)\end{array}$ & $\begin{array}{l}\text { Suicide } \\
(\mathrm{n}=103)\end{array}$ & $\begin{array}{c}\text { Natural causes } \\
\text { of death } \\
(n=131)\end{array}$ & $\begin{array}{l}\text { Accidents } \\
(\mathrm{n}=31)\end{array}$ & $\begin{array}{l}\text { Uncertain cause } \\
\text { of death } \\
(n=36)\end{array}$ \\
\hline Male sex & $1.81(1.33$ to $2 \cdot 12)$ & & $2.49(1.73$ to 3.56$)$ & & \\
\hline Increasing age & $1.04(1.03$ to 1.05$)$ & $1.03(1.01$ to 1.04$)$ & $1.06(1.104$ to 1.07$)$ & & \\
\hline Not employed & $1.40(1.05$ to 1.86$)$ & & & & \\
\hline Living alone & $1.50(1.13$ to 2.00$)$ & $2.28(1.48$ to 3.51$)$ & & & \\
\hline Two or more previous attempts & $1.55(1.29$ to 1.86$)$ & $2.25(1.48$ to 3.42$)$ & $1.97(1.16$ to 3.32$)$ & $4 \cdot 48(2 \cdot 17$ to $9 \cdot 27)$ & \\
\hline Drug abuse & $2.15(1.34$ to 3.46$)$ & & $2.72(1.06$ to 6.97$)$ & $4.41(1.67$ to 11.69$)$ & $11 \cdot 08(5.09$ to $24 \cdot 11)$ \\
\hline Pensioner & & & $1.69(1.08$ to 2.66$)$ & & $2.05(0.97$ to 4.35$)$ \\
\hline Respirator treatment at index attempt & & $0.43(0.19$ to 0.98$)$ & & & \\
\hline Global $\chi^{2}$ & 157.92 & $47 \cdot 76$ & $172 \cdot 03$ & $37 \cdot 32$ & $55 \cdot 14$ \\
\hline Standard mortality rate & 550 & 2930 & 236 & 1256 & 5459 \\
\hline
\end{tabular}

the young age groups $(25 \cdot 2$ for ages $25-34$ years, $1 \cdot 5$ for ages $75-84$ years, both sexes).

Table II shows the age specific suicide rates in the patient population. In all age groups the suicide rates were between 15 and 300 times higher than in the general population. Cause specific standard mortality rate (suicide) for the patient population was $2960\left(\chi^{2}=\right.$ $11879.32, \mathrm{df}=1 ; \mathrm{p}<0.0001)$. The cause specific standard mortality rate for accidents was $1256\left(\chi^{2}=\right.$ $329 \cdot 86, \mathrm{df}=1, \mathrm{p}<0.0001)$, and for uncertain causes it was $5459\left(\chi^{2}=1893, \mathrm{df}=1, \mathrm{p}<0.0001\right)$.

As shown in table II, young suicide attempters also had higher mortality rates from natural causes than the general population. The cause specific standard mortality rate (natural death) in the patient population was $236\left(\chi^{2}=103 \cdot 12, \mathrm{df}=1 ; \mathrm{p}<0.0001\right)$.

Male sex, drug addiction, two or more previous suicide attempts, living alone, not being employed, and increasing age were risk factors for death by all causes identified in the regression analysis (table III). Age did not have as great an influence as could be expected. In the general population the relative risk of dying from all causes with increasing age was approximately $1 \cdot 1,{ }^{3}$ but in those who attempted suicide the relative risk of dying from all causes with increasing age was 1.05 .

As is shown in table III, the high risk factors identified by regression analysis as predictors of suicide were having previously attempted suicide two or more times, increasing age, living alone, and not being treated in a respirator at the index attempt. Univariate analysis with the log rank test showed that manic depressive illness was predictive. Patients not employed or with schizophrenia tended to represent high risk groups, but the differences did not reach significance. Sex and misuse of alcohol or drugs were not predictive factors. Manic depressive psychosis lost its significance as a risk factor when it was controlled for.

A high risk group was identified, consisting of patients who fulfilled at least one of the following criteria: having manic depressive illness, living alone, or having two or more previous suicide attempts. Table IV shows the relation between these risk factors and later suicide. The sensitivity of all factors together was $60 \%$, the specificity was $61 \%$, and the predictive value of a positive high risk factor was $16 \%$.

Increasing age constituted a risk factor for dying a

TABLE IV-Relation between actual suicides and risk factors for suicide. Values are numbers of subjects

\begin{tabular}{lccc}
\hline & $\begin{array}{c}\text { Death by } \\
\text { suicide } \\
(\mathrm{n}=103)\end{array}$ & $\begin{array}{c}\text { Alive at follow up } \\
\text { or died from } \\
\text { other causes } \\
(\mathrm{n}=871)\end{array}$ & $\begin{array}{c}\text { Total } \\
(\mathrm{n}=974)\end{array}$ \\
\hline No risk factors & 41 & 534 & 575 \\
At least one risk factor & 62 & 337 & 399
\end{tabular}

${ }^{\star}$ Living alone, manic depressive psychosis, or two or more previous suicide attempts.
TABLE V-Suicide method for later suicide after suicide attempt by self poisoning. Values are numbers of subjects

\begin{tabular}{lcrc}
\hline & Both sexes & Men & Women \\
\hline Poisoning with solids or liquids & 56 & 23 & 33 \\
Domestic gas or car exhaust & 5 & 3 & 2 \\
Hanging, etc & 22 & 13 & 9 \\
Drowning, etc & 4 & 0 & 4 \\
Firearms & 5 & 5 & 0 \\
Cutting or piercing & 1 & 1 & 0 \\
Jumping or falling & 4 & 0 & 4 \\
Other or unspecified & 6 & 3 & 3 \\
\hline Total & 103 & 48 & 55 \\
\hline
\end{tabular}

TABLE VI-Observed and expected numbers of deaths from natural causes

\begin{tabular}{lcrrl}
\hline Cause of death & ICD codes & $\begin{array}{c}\text { No } \\
\text { observed } \\
(\mathrm{O})\end{array}$ & $\begin{array}{c}\text { No } \\
\text { expected } \\
(\mathrm{E})\end{array}$ & $\begin{array}{c}\text { O/E } \\
\text { ratio }\end{array}$ \\
\hline Neoplasm & $140-239$ & 32 & 18.93 & $1 \cdot 7^{\star \star}$ \\
Endocrine & $240-279$ & 2 & $0 \cdot 99$ & $2 \cdot 0$ \\
Nervous & $320-389$ & 2 & $0 \cdot 51$ & $3 \cdot 9^{\star}$ \\
Circulatory & $390-459$ & 33 & $25 \cdot 70$ & $1 \cdot 3$ \\
Respiratory & $460-519$ & 8 & $3 \cdot 76$ & $2 \cdot 1^{\star}$ \\
Digestive & $520-579$ & 8 & 1.96 & $4 \cdot 1^{\star \star \star}$ \\
Alcohol related & $303,571 \cdot 0,456 \cdot 0$, & 12 & $0 \cdot 62$ & $19 \cdot 4^{\star \star \star}$ \\
Othert & $577 \cdot 1,577 \cdot 3,577 \cdot 9$ & & & \\
Ill-defined conditions $\neq$ & $280-290,580-779$, & 9 & 1.33 & $6 \cdot 8^{\star \star \star}$ \\
& $7994-796$ & 31 & $1 \cdot 33$ & $23 \cdot 3^{\star \star \star}$
\end{tabular}

Ill-defined conditions

795-796

$\mathrm{p}<0.05, \star \star p<0 \cdot 01, \star \star \star$
tSingle cases of causes of death such as coarctatio aorta, glomerulonephritis, tSingle cases of cause

a $\$$ Sudden, non-violent death and those who were dead on admission to hospital with no suspicion of external factors (mortuus admissus).

natural death, as shown in table III; however, as shown in table II, a larger proportion of young people died from natural causes than in the general population. Patients of male sex, patients who were pensioners, patients with several previous suicide attempts, and patients with drug misuse were also at high risk.

Factors characterising patients at high risk of dying from accidents after a suicide attempt as compared with the whole group of patients (table III) were drug abuse or having more previous suicide attempts. Being a drug misuser or pensioner put patients at high risk of dying from uncertain causes of death.

In the group of 96 patients with psychoses (affective psychosis, schizophrenia, or psychogenic psychosis), 16 committed suicide, 11 by violent methods. A significantly greater number used violent methods to commit suicide than in the non-psychotic patient group $\left(\chi^{2}=4 \cdot 08, \mathrm{df}=1, \mathrm{p}<0 \cdot 05\right)$. Table $\mathrm{V}$ gives the suicide methods distributed by sex. Only 56 of 103 who committed suicide died from self poisoning with solids or liquids. No association was found between male sex and violent method.

The figure shows the probability of death from specific causes as a function of follow up time. Suicide is more common shortly after the suicide attempt, and $55 \%$ of those who died by suicide in the follow up 
Probability of death by specific causes as function of length of follow up of people who attempted suicide in Copenhagen in 1980

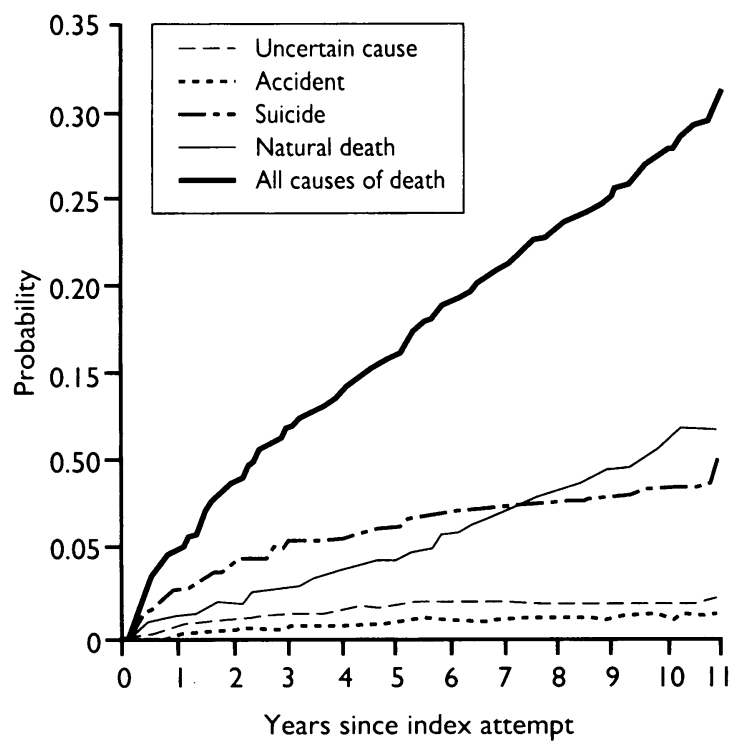

period died in the first two years after the index suicide attempt.

Table VI presents the observed and expected numbers of deaths from different natural causes. An unexpectedly high number of deaths were from causes other than circulatory diseases. Alcohol related deaths and ill defined conditions occurred unexpectedly often.

Alcoholism, drug misuse, more than two suicide atempts, male sex, and being treated with a respirator at the index attempt were risk factors that in Cox regression analysis predicted death by alcohol related causes. However, only seven out of 12 patients who died from alcohol related diseases had been diagnosed as alcoholic at the admission in 1980 .

\section{Discussion}

Patients surviving an attempted suicide in 1980 were at high risk of death from both natural and unnatural causes. The cause specific mortality (uncertain cause) was almost 60 times higher than in the general population, and mortality from suicide was about 30 times greater than in the general population, as evaluated by the standard mortality rate.

Although miscounting suicides has not been found to be so large that it would greatly affect the ranking of national suicide rates, ${ }^{21}$ the finding that death by uncertain causes and death by ill defined conditions occurred with an unexpected frequency indicates that misclassification has occurred. Drug misuse was the strongest predictor of death by uncertain causes (relative risk 11.08): it will often be difficult to determine whether a drug user has died of suicide, accident, natural causes, or even homicide.

More than two previous suicide attempts, increasing age, living alone, manic depressive illness, and not being treated in a respirator at the index attempt were high risk factors for successful suicide. The finding that patients who were not treated in a respirator at the index attempt were at increased risk of later suicide was marginally significant. This finding probably reflects that these patients had poor health and died from other causes-for example, alcohol related causes-but it might also indicate that a suicide attempt with a serious aftermath could protect against later suicide.

Contrary to the findings of many other studies, ${ }^{102122}$ alcoholism did not prove to be a factor predicting suicide, even though analysis of the data took into account that alcoholism might occur both as a first and second diagnosis. This could be due to the suicide rate also being high in the non-alcoholic part of the patient group, or to inexact classification.

In the general population, mortality by suicide in men is much higher than in women. Men and women in this study did not have different suicide rates. An explanation for this discrepancy with the figures for the general population might be that since men more often use violent and lethal methods for suicide attempts than women, the group studied might represent a selected group-namely, those who initially choose less lethal methods for their suicide attempt. The men in this study might represent a group less prone to choose lethal methods than the group of all men attempting suicide. This theory is in accordance with the lack of association between male sex and violent method of suicide found in this study.

The group had a significantly higher mortality from alcohol related illnesses and all types of physical diseases, except circulatory diseases, than the general population. This finding is in accordance with a follow up study in Stockholm which also showed an excessive mortality from causes other than suicide. ${ }^{6}$ In a large English study Hawton and Fagg found excessive mortality of different causes of death, even though these were not related to alcohol in particular. ${ }^{23}$ Only seven patients who died of alcohol related causes were diagnosed as alcoholics; this raises the question of whether misuse developed during the study period or whether alcoholism was misclassified in the records from 1980 .

Although high risk factors can be identified, a strategy of treating only the patients with these factors is not suitable for prevention of suicides. Only eight of the 103 patients who died by suicide had manic depressive illness, 27 patients had no mental illness, and 72 patients were not living alone. Although those with repeated suicide attempts were significantly more likely to succeed, for 46 of the 103 who died by suicide the index attempt was their first suicide attempt. Even when several different risk factors were combined the sensitivity was no more than $60 \%$, and specificity was $61 \%$. A special high risk group was difficult to identify.

The group of patients attempting suicide is, especially with regard to death by unnatural causes, a high risk group. Mortality, especially in young patients, increased dramatically when compared to the general population. Preventive efforts should be directed towards the whole group, and services directed towards this group of patients should be developed. Death from accidents, uncertain causes, and natural causes was also overrepresented in patients who had attempted suicide; this draws the attention to the overall high risk status of the group. The group may be characterised by lethal lifestyle and risk behaviour, or by poor health before the index suicide attempt. Another possible explanation is that factors overrepresented in the group who attempted suicide (such as living alone, not being employed, being mentally ill) are associated with increased mortality due to a decreased tendency to seek health services and to increased susceptibility. ${ }^{24}$

We thank the consultant service in methodology and statistics at the Danish Medical Research Council for helpful advice in data analysis; Karsten Jensen, chief of the Poisoning Treatment Centre at Bispebjerg Hospital, for critical comments on the manuscript; and Ego and Eli Larsens Foundation, the Foundation of Medical Department C, Bispebjerg Hospital, and Organon for economic assistance, which made the analysis of the study possible.

\footnotetext{
1 World Health Organisation. World health statistics annual 1990. Geneva: WHO, 1991

2 Kobenhavns Statistiske Kontor. Kobenhavns statistiske arbog 1980 /Copenhagen statistical yearbook 1980]. Copenhagen: Københavns Statistiske Kontor, 1981.

3 Danmarks Statistik (The Danish National Bureau of Statistics). Vital statistics 1989. Copenhagen: Danmarks Statistik, 1991.

4 Bratfos O. Attempted suicide. Acta Psychiatr Scand 1971;38:38-56.

5 Paerregaard G. Suicide among attempted suicides: a 10-year follow-up. Suicide
} $1975 ; 5: 140-4$ 
6 Ettlinger RW. Evaluation of the suicide prevention after attempted suicide. Acta Psvchiatr Siand 1975;260(suppl):84-99.

Dahlgren KG. Attempted suicides- 35 years afterward. Sucicide Life Thriat Behar 1977;7:75-9.

8 Rygnestad T. A prospective 5-year follow-up study of self-poisoned patients. Acta Psychiatr Scand 1988;77:328-31.

9 Sundqvist-Stensman UB. Suicides among persons treated for self-poisoning a an ICU. Opuscula Medica 1988;3:71-6.

10 Cullberg J, W'asserman D, Stefansson CG. W'ho commits suicide after a suicide attempt? An 8 to 10 vear follow up in a suburban catchment area Acta Psychiatr Scand 1988:77:598-603.

11 Suokas J, Lönnqvist J. Outcome of attempted suicide and psychiatric consultation: risk factors and suicide mortality during a five-year follow-up. Acta Psychiatr Scand 1991;84:545-9.

12 Nielsen B, Wang AG, Bille-Braha U. Attempted suicide in Denmark. IV. A five-year follow up. Acta Psychiatr Scand 1990;81:250-4

13 Ekeberg Ø, Fllingsen O, Jacobsen D. Suicide and other causes of death in a five-year follow-up of patients treated for self-poisoning in Oslo. Acta Psychiatr Scand 1991;83:432-7.

14 Bjaeldager PAL, Breum L, Munck IK, Nordestgaard A, Hunding A Salicylatforgiftninger i forgiftningscentralen i 1980 [Salicylat poisoning in centre for treatment of poisoning in 1980]. Ugeskr Lacger 1983;145:2833-7.

15 Kaplan MN, Meier P. Nonparametric estimation from incomplete observa- tions. Fournal of thi Americun Statistical Assuciation 1958;53:457-8

16. Cox DR. Regression models and life tables. If R Statist Soc B 1972;34 $187-220$

17 Breslow N, Day N. Indirect standardization and multiplicative models for rates, with reference to the age adjustment of cancer incidence and relative frequency data. 7 Chronic Dis 1975;28:289-303.

18 Sundhedsstyrelsen (Danish National Board of Health). Causes of death in Denmark 1980. Copenhagen: Danish National Board of Health, 1982

19 Andersen PK, Wæth M. Statistisk analyse af overlevelsesdate ved legevidenskabelige undersogelser [Statistical methods in survival analysis]. Copenhagen Odense, Arhus: FADL's Forlag, 1988

20 Lester D. Miscounting suicides. Acta Psychiatr Scand 1992;85:15-6.

21 Egmond EJ, Diekstra FRW. The predictability of suicidal behavior. The results of meta-analysis of published studies. In: Diekstra RFW, Maris R, Platt S, Schmidtke A, Sonneck G, eds. Sucide and its prevention. The role of attitudes and imitation. Copenhagen: World Health Organisation, 1989.

22 Kreitman N. Param

23 Hawton K, Fagg J. Suicide, and other causes of death, following attempted suicide. Br f Psychiatry 1988;152:359-66.

24 Goodwin JS, Hunt W'C, Key CR, Samet JM. The effect of marital status on stage, treatment, and survival of cancer patients. JAMA 1987;258:3125-30.

(Accepted 19 April 1993)

\title{
Factors associated with suicide after parasuicide in young people
}

\author{
Keith Hawton, Joan Fagg, Stephen Platt, Michael Hawkins
}

\section{Abstract}

Objective-To determine factors associated with completed suicide in young parasuicide patients.

Design-Case-control study.

Setting-Regional poisoning treatment centre in a teaching general hospital.

Subjects-Patients who, between 1968 and 1985 when aged 15-24 years, were admitted to the regional poisoning treatment centre because of deliberate self poisoning or self injury. Cases $(n=62)$ consisted of those who by the end of 1985 had died locally from either suicide $(n=41)$ or possible suicide $(n=21)$. Controls $(n=124)$ were patients who were known not to have died locally during the study period. Two controls were selected for each case, matched by sex, age (within two years), and length of follow up.

Main outcome measures-Possible predictors of completed suicide.

Results-Univariate analysis (conditional logistic regression) showed that risk of death due to suicide and possible suicide was associated with six factors: social class $V$ (odds ratio $2 \cdot 7,95 \%$ confidence interval $1 \cdot 1$ to $6 \cdot 7)$, unemployment $(2 \cdot 8,1 \cdot 4$ to $5 \cdot 8)$, previous inpatient psychiatric treatment $(4 \cdot 9,2 \cdot 2$ to $10.9)$, substance misuse $(3 \cdot 3,1.6$ to $6 \cdot 8)$, personality disorder $(2 \cdot 1,1.03$ to $4 \cdot 4)$, and previous attempted suicide $(2 \cdot 3,1 \cdot 2$ to $4 \cdot 4)$. Multivariate analysis identified two factors as significantly contributing to the model that best discriminated between the cases and controls: substance misuse (alcohol or drugs, or both) (adjusted odds ratio 3.9 ) and previous inpatient psychiatric treatment $(3 \cdot 7)$. These factors seemed to be associated with suicide after attempted suicide in both the short term (less than 12 months) and the long term (one year or more) and were also identified when the analysis was restricted to subjects who definitely died by suicide and their controls.

Conclusions-Suicide after parasuicide in young people is associated with substance misuse. This suggests that prevention of suicide in young people who attempt suicide might be improved by close liaison between general hospital services for patients who have attempted suicide and services for young substance misusers and by measures aimed at preventing substance misuse in young people.

\section{Introduction}

In the United Kingdom parasuicide (attempted suicide) is common in young people, particularly teenage girls and young men..$^{1-3}$ After parasuicide there is a considerable risk of eventual suicide. Within a year after a suicide attempt about $1 \%$ of adults die by suicide, and this risk remains increased several years later. ${ }^{45}$ The risk of suicide after parasuicide in adolescents, while probably lower than that of adults, is still considerable. In a group of 16-20 year old self poisoners followed up for a mean of $2 \cdot 8$ years in Oxford suicide or probable suicide occurred in $0.32 \%$. $^{\circ}$ An increased risk of suicide has been found in other studies, probably reflecting different characteristics of the initial cohort; for example, suicides occurred in $4.3 \%$ of Swedish adolescents who attempted suicide and were followed up for 10-15 years. ${ }^{7}$

If positive steps are to be made towards achieving targets in The Health of the Nation regarding suicide prevention ${ }^{\mathrm{x}}$ it is important to try to identify risk factors for suicide after parasuicide in the young, especially in the light of the recent rise in rates of completed suicide by young men" and the high proportion of young people who commit suicide who have previously attempted suicide. ${ }^{10}$ Although there is considerable knowledge of risk factors for suicide after parasuicide by adults, ${ }^{511-13}$ this is not so for the young, among whom only relatively older age, male sex, violent attempts, and bipolar or psychotic (probably schizophrenic) disorder have so far been identified as risk factors. ${ }^{6}$

We report a case-control study of suicide after parasuicide in young people (15-24 years). Cases had died by suicide or likely suicide after parasuicide. Controls were selected from patients who had attempted suicide, matching for age, sex, and length of follow up (up to 18 years). Our objective was to identify factors associated with future suicide.

\section{Method}

SOURCE OF DATA

Subjects for the study were identified from the computerised data file maintained until recently by the Medical Research Council Unit for Epidemiological Studies in Psychiatry in Edinburgh for monitoring parasuicide patients referred to the Regional Poisoning Treatment Centre at Edinburgh Royal Infirmary. Earlier work showed that about $83 \%$ of attenders at the Royal Infirmary's accident and emergency department whose behaviour met the definition for parasuicide (see below), were admitted to the centre. ${ }^{14}$ Of those admitted, about $91 \%$ were interviewed by a psychiatrist, who 